\title{
La "Concesión Vascongada» y los antecedentes de la línea ferroviaria del Norte (1884-1855)
}

\author{
Carlos larrinaga Rodríguez \\ Universidad del País Vasco
}

The "Concesión Vascongada" and the record sing of the
Nothern Railway (1844-1855)

\section{RESUMEN}

Tras promulgarse la Real Orden de 31 de diciembre de 1844 , que pasó a regular las concesiones ferroviarias, la burguesía de Vizcaya solicitó la concesión de una línea férrea entre Madrid e Irún pasando por Bilbao con el objeto de mejorar sus comunicaciones con el norte de Castilla. Fue la llamada "Concesión Vascongada", la cual, con el tiempo, llegaría a convertirse en el antecedente de la futura línea del Norte. La iniciativa, sin embargo, no tuvo éxito. Precisamente en este artículo se pretenden estudiar las causas de este fracaso, asi como las grandes expectativas que un proyecto de estas características generó en el norte de España.

PALABRAS CLAVE: Ferrocarril, Comercio, Burguesia vizcaina, Norte de España.

\section{ABSTRACT}

After being declared the Real Order in December 31 st 1844 , that regulates the railway concessions, the middle class of Biscay, requested the concession of a line between Madrid and Irun, passing through Bilbao, aiming to improve the communications with the north of Castile. This one was called "the Basque concession" and in the course of the time, became the antecedent of the future line of the North. However, this initiative was not successful. We want to study in this paper the reasons of this failure, as well as the great expectations this project created in the North of Spain.

\section{KEYWORDS:}

Railway, Commerce, Biscayan bourgeoisie, North of Spain.

\section{INTRODUCCIÓN}

Desde fechas muy tempranas la burguesía vizcaína supo apreciar las posibilidades que los caminos de hierro podían tener para su desarrollo económico, vistas las ventajas que ofrecian respecto de los medios de transporte tradicionales y empeñados en mejorar sus vias de comunicación con Castilla. De ahí que muy poco 
después de promulgada la Real Orden de 31 de diciembre de 1844, que pasó a regular las concesiones ferroviarias a falta de una ley general de ferrocarriles, la burguesía bilbaína solicitara la concesión de un ferrocarril entre Madrid e Irún pasando por Bilbao. Fue la llamada "Concesión Vascongada", la cual, a la postre, se convirtió en verdad en el precedente de la ulterior línea férrea del norte de España. Es nuestra intención, pues, en este trabajo estudiar el devenir de esta importante concesión que, como tantas otras en España, terminaría fracasando ante la falta de un marco institucional adecuado y de unos capitales suficientes para llevarla a cabo.

\section{HACIA LA REAL ORDEN DE 31 DE DICIEMBRE DE 1844}

El final de la Primera Guerra Carlista provocó una inquietud general por el restablecimiento de los caminos interiores afectados por las consecuencias de la contienda. En concreto, esta preocupación fue especialmente visible en el ámbito mercantil, pudiéndose recordar que incluso los comerciantes madrileños llegaron a solicitar del Gobierno la creación de un ministerio para tal fin ${ }^{1}$. Sin duda, esta preocupación debió proyectarse también hacia los ferrocarriles, ya que, como ha puesto de manifiesto Diego Mateo del Peral, era frecuente leer en la prensa de esos años noticias sobre el desarrollo ferroviario de otros países, haciendo referencias favorables a su implantación en España. A su vez, semejante necesidad se vio alimentada por las crónicas de los diversos corresponsales que insistían en la eficacia de las nuevas vías de transporte en el desarrollo económico ${ }^{2}$. Como se sabe, las ventajas de los ferrocarriles sobre los medios de comunicación tradicionales radicaban en la autonomía respecto de la fuerza animal, en la mayor regularidad, mayor velocidad, mayor capacidad de carga y menor coste, aspectos todos ellos que habian empezado a ponerse de manifiesto en la apertura de la línea Manchester-Liverpool en 1830 y que no pasaron desapercibidos a los comerciantes y viajeros españoles en Gran Bretaña.

Asimismo destacarían los informes técnicos de Ramón de la Sagra, economista y diputado que, comisionado a principios de la década de 1840 por el Gobierno español, realizó un viaje por Francia, Bélgica y Alemania con el fin de estudiar el desarrollo económico de estos países. En sus informes De la Sagra insistía, precisamente, en las ventajas que los ferrocarriles suponían para el incremento del comercio y la solidaridad entre los pueblos. Es más, vinculaba los adelantos de estos países con el fomento de las vías de comunicación, denunciando la carencia de una acción similar en España ${ }^{3}$. Siendo esto cierto, la verdad es que la actitud del Gobierno español no fue excepcional, ya que esta indiferencia de la administración ante las solicitudes ferroviarias se dio también inicialmente en

1 Guía del Comercio y Boletín de Fomento, n. ${ }^{0} 11,16-3-1842$, p. 2, cit. Mateo del Peral (1978), p. 34.

2 Mateo del Peral (1978), p. 34.

3 Mateo del Peral (1978), p. 5. 
Gran Bretaña y Francia, donde las compañías construyeron las líneas gracias a sus propios recursos y al margen de la ayuda o protección estatal ${ }^{4}$.

En España los primeros intentos de construcción de líneas férreas tuvieron lugar a finales de la década de 1820 , es decir, poco después de que se pusiera en marcha el primer ferrocarril del mundo, el que unia las localidades inglesas de Darlington y Stockton. No es extraño, pues, que una vez concluida la guerra carlista, volvieran a surgir nuevas iniciativas ferroviarias. Al respecto, no podemos olvidar el propio desarrollo económico que a principios de la década de 1840 afectó a algunas regiones españolas, en especial a Cataluña, País Vasco y Valencia. Es, pues, en este contexto de prosperidad donde debemos señalar estas tentativas. Así, en 1843 el barcelonés José María Roca, comerciante asentado en Londres, suscribió en representación de una compañía de notables una propuesta para construir un camino de hierro de 28 kilómetros entre la capital del Principado y Mataró, la cual tuvo buena acogida por parte del gobierno provisional de Joaquín M. ${ }^{a}$ López. De hecho, el proyecto fue adelante y no habiendo transcurrido aún dos años se anunciaba ya el comienzo de las obras del que habría de ser el primer ferrocarril de la península, inaugurado en 1848.

El ejemplo de Roca tuvo éxito y suscitó el interés de otros promotores, como fue el caso del ingeniero Pedro de Lara, quien, en abril de 1844, obtuvo la concesión provisional de la línea de Madrid a Aranjuez, cuya prolongación hasta Alicante le fue otorgada por una Real Orden de 14 de agosto de ese mismo año. Ahora bien, también en 1844 el ingeniero francés Jean Charles Jacqueau Galbrun, quien actuaba en representación de un grupo financiero de París, presentó una propuesta de construcción de un ferrocarril entre Madrid y Cádiz de $665 \mathrm{~km}$ de longitud y una inversión de 135 millones de francos ${ }^{5}$. Es más, cuando aún no era pública la resolución sobre esta línea, otro extranjero, esta vez el británico Richard Keily, elevaba al Ministerio de Gobernación el 8 de noviembre de 1844 su propuesta de construcción de un ferrocarril de doble vía entre la capital del reino y el puerto asturiano de Avilés pasando por León. Keily actuaba como apoderado de una empresa que, en el caso de prosperar el proyecto, llevaría por nombre el de "Compañía del Real Camino de Hierro del Norte de España", cuyo capital previsto ascendía a dos millones de libras esterlinas y cuya presidencia la ejercería José de Salamanca. Por lo tanto, Keily no era sino un mero intermediario de un grupo inversor británico formado por Joshua Walmsley, John Abel Smith y el ingeniero George Stephenson ${ }^{6}$. La importancia de esta línea estaba clara, ya que implicaba la comunicación de la costa cantábrica con la capital de España, pudiendo llegar a dejar en una situación marginal a localidades como Santander, Bilbao o San Sebastián, las cuales habían tratado de mejorar sus accesos a Madrid y a la submeseta norte desde el último tercio del siglo XVIII.

\footnotetext{
4 Cameron (1971), pp. 196 y ss.

5 WaIS $\left(1987,3 .^{\star}\right.$ ed. $)$, pp. 38-39.

6 Casares (1973), pp. 66-67.
} 
Sin duda, las peticiones de Galbrun y de Keily y de los demás promotores, así como la presión de la opinión pública, hicieron que el Gobierno empezara a interesarse más seriamente por el tema de los ferrocarriles, ya que hasta finales de 1844 daba la sensación de que la Administración se había mostrado indiferente al establecimiento de un nuevo sistema de comunicaciones cada vez más extendido en Europa occidental. Sin embargo, para entonces aquélla estaba ya en condiciones de establecer una normativa ferroviaria y de aprovechar la ocasión brindada por los capitalistas extranjeros, puesto que por las Reales Ordenes de 14 de abril de 1836 y 11 de abril de 1844 quedó fijada la planta de la Dirección General de Caminos, Canales y Puertos y las atribuciones de los funcionarios de carrera pertenecientes al Cuerpo de Ingenieros Civiles ${ }^{7}$. El Gobierno moderado de Narváez se enfrentaba, pues, a un vacío legal al que era preciso hacer frente, de suerte que se nombró una Comisión de Ingenieros de Caminos de la Dirección General del Ramo formada por Juan Subercase, Calixto Santa Cruz y José Subercase para que realizaran un informe al respecto. El texto fue dado el 2 de noviembre de 1844 y no es extraño, por lo tanto, que Pedro José Pidal, a la sazón ministro de la Gobernación, anunciara el 23 de ese mismo mes en el Congreso de los Diputados que dicha Dirección General de Caminos estaba trabajando en los reglamentos y métodos de los caminos ordinarios y de hierro ${ }^{8}$. Precisamente, el denominado "Informe Subercase" serviría de base para la Real Orden dictada por el Gobierno el 31 de diciembre de 1844 y estaría firmada por el propio Pidal.

A falta de una ley general de ferrocarriles, no aprobada hasta 1855, esta Real Orden vendría a regular a partir de entonces todo lo relacionado con las concesiones, estableciéndose las reglas a observar en la tramitación de las solicitudes y regulándose el conjunto de requisitos generales para la concesión, mediante la aprobación de un pliego de condiciones generales y un modelo de tarifa. Las obligaciones estipuladas en esta Real Orden manifestaban una inicial firmeza del Estado en velar por los intereses públicos. Esto no fue óbice para que se otorgaran determinadas facilidades a la iniciativa privada, lo cual creó una imagen de cierta especulación, que, según Diego Mateo del Peral, nunca llegó a producirse. No obstante, es verdad que desde el 31 de diciembre de 1844 hasta el 31 de diciembre de 1846 se concedieron más de $6.500 \mathrm{~km}$, si bien de las veintitrés líneas otorgadas sólo subsistieron cuatro, con una longitud total de cerca de $186 \mathrm{~km}$, lo que representaba algo menos del $3 \%$ del total autorizado ${ }^{9}$.

\footnotetext{
${ }^{7}$ WAIS $\left(1987,3 .{ }^{a}\right.$ ed.), pp. 35-38.

8 Mateo del Peral (1978), p. 39.

9 Mateo del Peral (1978), p. 44. Véanse también Casares (1973), pp. 60-61 y VVAA (1998), vol.1, pp. 37-41.
} 


\section{LA CONCESIÓN DEL MADRID-IRÚN POR BILBAO DE 16 DE AGOSTO DE 1845}

En este marco de euforia o frenesí ferroviario es preciso situar los orígenes de la línea del norte de España, es decir, de ese camino de hierro que originalmente debía enlazar Madrid con Irún por Bilbao y que fue auspiciado por la $\mathrm{Di}$ putación de Vizcaya, el Ayuntamiento de Bilbao y la Junta de Comercio de esta localidad. Hablamos, precisamente, de lo que se llegó a llamar la "Concesión Vascongada", propuesta que estuvo ya en marcha desde enero de 1845, inmediatamente después de que hubiera sido dictada la Real Orden de 31 de diciembre de 1844. La celeridad de la misma no fue casual, sino que estuvo motivada por la citada petición de Richard Keily de construir un ferrocarril entre la capital del reino y Avilés, con las consecuencias ya mencionadas para el resto de ciudades del Cantábrico.

En concreto, los comerciantes de Bilbao estaban prestos a mejorar sus comunicaciones con Castilla mediante una línea férrea desde finales de la década de 1820, constituyendo una auténtica amenaza para sus intereses el hecho de que pudiera construirse la línea de Avilés. Al menos así lo había puesto de manifiesto el diputado a Cortes José María Orense en un oficio enviado a la Junta de Comercio de Bilbao. En él se daba cuenta de esa propuesta extranjera y se advertía de los graves perjuicios que sobrevendrian a esa plaza si no se apresuraba a abrir otro camino de hierro que pusiera a la capital vizcaína en comunicación con el interior peninsular. José Maria Orense añadía que, para ello, sería preciso solicitar la protección del Gobierno y que, si se lograsen reunir unos cien millones de reales, que aproximadamente vendrían a suponer la mitad del coste de la obra, sería más sencillo hallar quien facilitase los otros cien millones restantes. Sin duda, esta idea de Orense fue bien recibida en la Junta de Comercio, la cual llegó a redactar una circular para tratar de interesar a las diputaciones de las provincias próximas. Además, los comerciantes bilbainos no sólo se reunieron con el Ayuntamiento de la villa, sino también con el Capitán General del distrito. Así, la Junta llegó a formar una comisión formada por Pedro Pascual Uhagón y Gabriel M. ${ }^{\mathrm{a}}$ de Ybarra para entender en este asunto. Lo mismo hizo el Ayuntamiento, cuya comisión estuvo formada por el propio alcalde, Federico Victoria de Lecea, y Manuel M. ${ }^{a}$ Uhagón ${ }^{10}$.

Al día siguiente de esta importante sesión municipal, el 31 de diciembre, a la vez que se promulgaba la Real Orden mencionada, el Gobierno otorgaba la concesión del ferrocarril de León a Avilés ${ }^{11}$, lo que hacía que el peligro para el comercio vizcaíno fuera ya inminente, ya que si se llevaba a cabo la prolongación hasta Madrid, como era de suponer, buena parte del tráfico cantábrico se canalizaría por Asturias, en detrimento del Señorio. A partir de este momento las más fu-

${ }^{10}$ Archivo Foral de Vizcaya (AFV): Municipal, Bilbao, Sec. 2. ${ }^{a}, 0208 / 004:$ sesión del Ayuntamiento de Bilbao de 30 de diciembre de 1844.

${ }^{11}$ WaIS $\left(1987,3 .{ }^{a}\right.$ ed. $)$, p. 69. 
nestas perspectivas auguradas por José María Orense parecían hacerse realidad. De ahí que inmediatamente las autoridades y los comerciantes vizcaínos se pusieran manos a la obra en el proyecto del Madrid-Irún por Bilbao. Ahora bien, el peligro no sólo se cernia sobre los intereses vizcaínos, sino también sobre los de otras provincias del norte, tal como lo demuestran las cartas enviadas por las diputaciones de Burgos, Álava y Palencia a la Junta de Comercio de Bilbao en enero de 1845 ofreciendo su colaboración en las gestiones que se realizaran ante el Gobierno ${ }^{12}$. Lo cual parece poner de manifiesto que en España cada vez era más evidente la necesidad de mejorar los medios de transporte terrestres, confiando en las posibilidades que el ferrocarril ofrecía en este campo ${ }^{13}$.

Por lo demás, y tal como sucediera con las otras dos instituciones mencionadas, el 21 de enero de 1845 también la Diputación de Vizcaya nombró una comisión, formada por Antonio Arguinzóniz y José Miguel Arrieta Mascárua, con el fin de presionar al Gobierno para la obtención de la línea ${ }^{14}$. De hecho, el ejecutivo no parecía descartar la idea de que pudiera aprobarse un ferrocarril entre Madrid y la frontera francesa, dado que la línea de Avilés no permitía el enlace con el pais vecino. En este sentido, parecía una actitud sumamente inteligente el plantear un nuevo ferrocarril entre la capital de España y Francia, a pesar de que sus intereses estuvieran centrados, fundamentalmente, en el mercado interior.

Si bien es verdad que éste era un anhelo que venía de atrás, desde las primeras propuestas que buscaban empalmar Bilbao con Burgos por el valle del Cadagua y Valmaseda, lo cierto es que en estos momentos este deseo cobraba mayor fuerza a raíz de la nueva situación económica generada con el decreto de Espartero de 29 de octubre de 1841, en virtud del cual las aduanas ubicadas en el interior de las provincias vascas pasaban a localizarse en la costa y en la frontera. Esta venía a ser una antigua reivindicación de la burguesía vasca, en especial donostiarra, que cada vez soportaba peor el hecho de que sus productos fueran gravados a la hora de entrar en el resto de los territorios de la Monarquia. De esta forma, aprovechando una revuelta auspiciada por los Moderados, y cuyo epicentro se situó en el País Vasco y Navarra, Espartero firmó este decreto en Vitoria, trasladando las aduanas a Irún, Fuenterrabía, Pasajes, San Sebastián, Guetaria, Deva, Bermeo, Plencia y Bilbao. A partir de ese momento, ese deseo de "españolizar" los productos vascos se hizo realidad, de suerte que las posibilidades para los empresarios vascos aumentaron considerablemente. Es cierto que no podemos hablar de una única causa a la hora de explicar el desarrollo económico vivido por el País Vasco desde entonces, pero la verdad es que este desplazamiento de las aduanas debió jugar un papel destacado. Al menos,

12 Archivo de la Cámara de Comercio de Bilbao (ACCB): Fondo Victoria de Lecea, legajo 9B, docs. $n .{ }^{\circ} 1,2$ y 3 : sendas cartas de las diputaciones de Burgos (10-1-1845), Álava (10-1-1845) y Palencia (181-1845).

13 Casañas (1977), p. 45.

14 AFV: Administrativo, Obras, transportes y comunicaciones: Ferrocarril Madrid-Irún, Registro 1, legajo 1: acta de 21 de enero de 1845. 
asi parece deducirse de un buen número de autores del siglo XIX que escribieron sobre esta relación ${ }^{15}$.

Qué duda cabe que desde 1842 las expectativas de los comerciantes y de los productores vascos aumentaron notablemente, aunque más aún incluso tras la finalización de la regencia de Espartero en mayo de 1843 y la llegada de los Moderados al poder en 1844, con quienes las instituciones vascas parecían congeniar mejor. Es precisamente en esta inédita situación económica generada a partir del traslado de aduanas y en este nuevo clima de entendimiento político entre las instituciones vascas y las autoridades de Madrid inaugurado en 1844 en el que debemos situar los orígenes de la moderna industrialización vasca y las nuevas necesidades de construir un camino de hierro entre Madrid e Irún pasando por Bilbao. En este sentido, la aprobación de la propuesta de Keily no hizo sino acelerar la negociación con el Gobierno.

Paralelamente a estas conversaciones, la Comisión del ferrocarril se había dirigido a las distintas instituciones locales (ayuntamientos y diputaciones) del norte del país y a la Junta de Comercio de Madrid para recabar fondos con vistas a financiar el estudio del proyecto, de forma que éste pudo ser costeado con el apoyo de algunas de estas entidades ${ }^{16}$. Así, para su puesta en marcha se pensó en que fueran técnicos extranjeros los que lo llevaran a cabo, por lo que los vizcaínos se relacionaron con el ingeniero inglés William Mackenzie, ingeniero, empresario de caminos y director de varios ferrocarriles. De esta forma la Comisión del ferrocarril entró en contacto con un grupo de ingenieros ingleses, entre los que destacaba un discípulo de George Stephenson, Alexander Ross, quien se encargó de la supervisión de los estudios, los cuales corrieron a cargo de los ingleses Lowe, Wilson, que se encargaría de la sección entre Bilbao e Irún, y Tate, ingeniero en jefe y presidente de la comisión científica encargada del trazado de la línea. Éstos partieron de Inglaterra el 26 de mayo, poniéndose manos a la obra inmediatamente ${ }^{17}$. De esta forma, el recorrido propuesto por dichos técnicos atravesaba Valladolid, Burgos, el corredor del Cadagua, Bilbao y San Sebastián y el costo estimado era de unos quinientos millones de reales de vellón. Una vez más observamos ese deseo de la burguesía local de reforzar las conexiones comerciales con el interior peninsular en la línea de lo ya expuesto.

A estos estudios puestos en marcha y al apoyo recibido por otras provincias se sumaron las reuniones sostenidas por Victoria de Lecea y Arrieta Mascárua en Madrid con el fin de obtener la concesión del camino de hierro entre Madrid e Irún. Así, además de los contactos mantenidos con el propio Gobierno, destacarían los apoyos prestados por Manuel Mazarredo, hombre de prestigio en las filas del

15 LARRINAGa (1999), pp. 28-32.

16 ACCB: Fondo Victoria de Lecea, legajo $9 B$, docs. $n .{ }^{\circ} 5,6,7,8,9,10,11,12,14,15,16,23,25,28$, $29,30,51$.

17 ACCB: Fondo Victoria de Lecea, legajo 9B, doc. n. ${ }^{\circ} 40$ : carta del 20 de mayo de 1845 de R. H. Stroerly (?), en nombre de Mackenzie, a F. Victoria de Lecea. 
moderantismo y futuro presidente de la compañía, y el propio duque de Riansares $^{18}$. De hecho, la negociación llegó a buen puerto, ya que la concesión de la línea fue otorgada por Real Orden el 16 de agosto de 1845 a Victoria de Lecea y Arrieta Mascárua como representantes de las autoridades y capitalistas de la villa de Bilbao.

En el pliego de condiciones particulares a que se refería dicha concesión se les obligaba a depositar en el Banco Español de San Fernando o en el de Isabel II el $10 \%$ en efectivo de las acciones que se emitieran en el plazo de dieciocho meses y se fijaba un plazo de sesenta días para efectuar el depósito de cinco millones de reales en una de esas dos entidades y el cumplimiento de las demás formalidades para que aquélla fuera válida. Esto precipitó las gestiones, de manera que para el 6 de octubre se había conseguido semejante suma de dinero, aportado por capitalistas vascos y madrileños ${ }^{19}$. Ese mismo mes, una Real Orden del día 14 declaraba que el camino de hierro debía pasar por Bilbao, Burgos, Palencia, Valladolid y Segovia.

\section{FORMACIÓN DE LA EMPRESA DEL CAMINO DE HIERRO DE MADRID A IRÚN POR BILBAO}

Una vez otorgada la concesión, reunido el capital necesario para el depósito y contratados los servicios de ingenieros británicos para delimitar el trazado de la vía, el siguiente paso habría de consistir en la creación de una compañía encargada de llevar a cabo el proyecto. Posiblemente la burguesía vizcaína pudiera asumir una importante suma del coste de las obras, pero no toda, por lo que resultaba necesario encontrar socios extranjeros dispuestos a invertir en este proyecto. La tarea no era fácil y las presiones fueron constantes. En efecto, el mismo día que se les dio la concesión, Mackenzie se dirigía a la Comisión del ferrocarril Madrid-Irún para informar de la reunión y proposición de fusión que le habían hecho los concesionarios de la denominada Compañía del ferrocarril del Norte de España, es decir, del camino de hierro de Madrid, Valladolid y Santander, aliados con los propietarios del Canal de Castilla ${ }^{20}$. El objetivo de Joshua Walmsley, principal impulsor de este proyecto, era la fusión de intereses y la creación de una sola empresa ferroviaria con un capital social de unos cuatro millones de libras esterlinas. La opera-

${ }^{18}$ ACCB: Fondo Victoria de Lecea, legajo 9B, doc. $n .^{\circ} 57$ : carta del 13 de julio de 1845 de $F$. Victoria de Lecea y J. M. Arrieta Mascárua a la Comisión del ferrocarril informando, entre otras cosas, de los servicios prestados por M. Mazarredo; y doc. $n .^{\circ}$ 59: carta del 24 de julio 1845 del duque de Riansares a $F$. Victoria de Lecea y J. M. Arrieta Mascárua.

19 GonzÁlez PORTILLA y otros (1995), p. 90 y Empresa del camino de fierro de Madrid á Irun por Bilbao, Imprenta y litografía de Delmas e Hijo, Bilbao, 1846, Título II, art. 5. ${ }^{\circ}$. En concreto, el depósito se hizo en el Banco de San Fernando de Madrid.

20 Hay que recordar que el 16 de abril de 1845 Gaspar de Remisa recibió, junto con el duque de Sotomayor y una compañía inglesa, la concesión para construir un ferrocarril entre Santander y Valladolid, pasando por Alar del Rey, habiendo obtenido aquél hacia tres lustros la concesión del Canal de Castilla (Véase SÁnchez-Albornoz (1969), pp. 119-120). 
ción era de envergadura, ya que, además del propio Walmsley, se encontraban importantes hombres de negocios ingleses y franceses, tales como Collet, Jackson, Reed, Laffitte, Blount y Brassey ${ }^{21}$. A este respecto, cabe destacar que el empeño de Walmsley fue tal que incluso convenció al mismo George Stephenson para desplazarse a España con el fin de examinar el trazado de la futura vía férrea. De hecho, de camino a Santander, fue cuando aquél se entrevistó con Mackenzie para proponerle su idea de fusión. Una vez en suelo español, Stephenson recorrió el terreno por donde habría de pasar la futura línea, si bien, finalmente, el proyecto terminó fracasando por la falta de recursos ${ }^{22}$.

Mientras, dos de los miembros de la llamada Comisión del camino de hierro de Irún a Madrid por Bilbao, encargada de llevar a cabo lo dispuesto en la Real Orden de 16 de agosto, Federico Victoria de Lecea y Pedro Pascual Uhagón, se desplazaron en octubre de 1845 a París. Aquí se entrevistaron con William Mackenzie, teniendo que hacer frente al mismo tiempo a las fuertes presiones de los representantes de la Compañía del ferrocarril del Norte de España ${ }^{23}$. Así las cosas, los comisionados vizcaínos no lograron formalizar una sociedad debido al estado de las bolsas extranjeras respecto de los valores ferroviarios, que en esos momentos estaban atravesando una fuerte crisis. A lo más que se llegó entonces fue a la firma de un convenio provisional entre los representantes vizcainos y Mackenzie el 12 de diciembre. Se trataba de un contrato por el cual se acordaba el establecimiento de una sociedad anónima que explotara el ferrocarril de Madrid a Irún por Bilbao, aunque, como ya se ha dicho, tenía carácter provisional y estaba sometido a la aceptación y ratificación del empresario ferroviario Juan David Barry ${ }^{24}$. En este sentido, Mackenzie había sido partidario de aplazar la creación de la sociedad debido a la crisis bursátil de ese momento, pero Victoria de Lecea y Uhagón tenian prisa por conseguir un acuerdo concluyente y lograr la creación de una sociedad. De hecho, la firma del acta definitiva de la constitución de la anónima "Compañía del camino de fierro de Madrid á Irun por Bilbao" tuvo lugar en la capital francesa el 26 de enero del año siguiente, aunque hubo que esperar hasta la primavera para que la compañía fuera aprobada en España ${ }^{25}$.

En cualquier caso, mientras Victoria de Lecea y Uhagón negociaban en la capital francesa, en Bilbao estalló la crisis entre los propios capitalistas que habian impulsado el proyecto, al ser cuestionada la gestión llevada a cabo por la comisión formada al efecto. Las críticas esgrimidas fueron dos. Por un lado, se decía que la sociedad se habia comprometido no sólo a construir el ferrocarril, sino también a

${ }^{21}$ ACCB: Fondo Victoria de Lecea, legajo 9B, doc. n. ${ }^{\circ} 64$ : carta del 16 de agosto de 1845 de Mackenzie al presidente de la Comisión del ferrocarril.

${ }^{22}$ WAIS (1987, 3. ed.), pp. 45-47.

23 ACCB: Fondo Victoria de Lecea, legajo 9B: docs. $n .{ }^{\circ} 77,79$ y 89: sendas cartas del 11,13 y 23 de octubre de $1845 \mathrm{~F}$. Victoria de Lecea y $\mathrm{P}$. P. Uhagón a la comisión del camino de hierro de Madrid a Irún por Bilbao.

${ }^{24}$ ACCB: Fondo Victoria de Lecea, legajo $8 \mathrm{~A}$, doc. $n .{ }^{\circ}$ 12: contrato ratificado por Barry el 25 de diciembre de 1845 en París.

${ }^{25}$ AFV: Municipal, Bilbao, Secc. 2. ${ }^{\circledR}, 0208 / 004$. 
arreglar el puerto de Bilbao, estimando que la compañía se estaba arriesgando en funciones que correspondían a las instituciones públicas. Por otro, se criticó que los comisionados dispusieran de unos privilegios para los que no estaban autorizados en su calidad de representantes. Estas desavenencias hicieron que 24 de los socios fundadores bilbaínos abandonaran el proyecto, permaneciendo 19 socios domiciliados en Bilbao y otros dos en las localidades vizcaínas de Durango y Güeñes. Por su parte, la representación madrileña ascendía a 21 socios y otros procedían de Burgos y Valladolid, respectivamente ${ }^{26}$.

No obstante, esta crisis no fue un obstáculo para que se constituyera la sociedad. Más aún, el hecho de que en la formación de esta compañía tomaran parte sobresalientes capitalistas locales, madrileños y extranjeros pone de manifiesto la trascendencia que este proyecto ferroviario tenia para las instituciones vizcainas, así como la importancia otorgada por los reputados inversores extranjeros, quienes vieron las posibilidades que podía tener la construcción de un camino de hierro entre la capital del reino y la frontera francesa, tocando, además, un destacado puerto cantábrico y una provincia, Vizcaya, donde se habia puesto en marcha el proceso de industrialización. Conviene, por lo tanto, analizar los miembros del primer consejo de administración de la empresa para confirmar lo dicho hasta ahora.

Miembros del consejo de administración de la Compañía del camino de fierro de Madrid á Irun por Bilbao en 1846

\begin{tabular}{|c|c|c|c|}
\hline Miembro & Domicilio & Profesión y distinciones & Cargo \\
\hline \multicolumn{4}{|l|}{ ESPAÑA } \\
\hline * Manuel de Mazarredo & Madrid & $\begin{array}{l}\text { Teniente General, propietario y } \\
\text { senador }\end{array}$ & Presidente \\
\hline * Federico Victoria de Lecea & Bilbao & Ex diputado a Cortes y propietario & Vice-presidente \\
\hline * Juan Manuel Calderón & Madrid & $\begin{array}{l}\text { Consiliario del Banco Español de } \\
\text { S. Fernando y banquero }\end{array}$ & \\
\hline *Jaime Ceriola & Madrid & $\begin{array}{l}\text { Consiliario del Banco Español de } \\
\text { S. Fernando y banquero }\end{array}$ & \\
\hline * Manuel Cantero & Madrid & $\begin{array}{l}\text { Director de la sociedad del Anco- } \\
\text { ra y banquero }\end{array}$ & \\
\hline * Antonio Arguinzóniz & Bilbao & $\begin{array}{l}\text { Ex diputado general de Vizcaya } \\
\text { y propietario }\end{array}$ & \\
\hline *Tomás José de Epalza & Bilbao & $\begin{array}{l}\text { Comisionado del Banco de Isabel } \\
\text { Il y banquero }\end{array}$ & \\
\hline * Guillermo de Uhagón & Bilbao & Capitalista y propietario & \\
\hline "Pedro Pascual de Uhagón & Bilbao & $\begin{array}{l}\text { Comisionado del Banco de } \mathrm{S} \text {. } \\
\text { Fernando y comerciante }\end{array}$ & \\
\hline
\end{tabular}

${ }^{26}$ González Portilla y otros (1995), p. 93. 
Miembros del consejo de administración de la Compañía del camino de fierro de Madrid á Irun por Bilbao en 1846 (continuación)

\begin{tabular}{|c|c|c|c|}
\hline Miembro & Domicilio & Profesión y distinciones & Cargo \\
\hline $\begin{array}{l}\text { * Gabriel M.a de Orbegozo } \\
\text { * J. Miguel Arrieta Mascárua } \\
\text { * Manuel M.a de Uhagón }\end{array}$ & $\begin{array}{l}\text { Bilbao } \\
\text { Bilbao } \\
\text { Bilbao }\end{array}$ & $\begin{array}{l}\text { Comerciante } \\
\text { Ex diputado a Cortes y propietario } \\
\text { Consejero de provincia de Vizca- } \\
\text { ya y propietario }\end{array}$ & $\begin{array}{l}\text { Secretario } \\
\text { Secretario }\end{array}$ \\
\hline \multicolumn{4}{|l|}{ FRANCIA } \\
\hline $\begin{array}{l}\text { * E. C. Felipe de Noailles, du- } \\
\text { que de Mouchy } \\
\text { ^Juan David Barry }\end{array}$ & $\begin{array}{l}\text { París } \\
\text { París }\end{array}$ & $\begin{array}{l}\text { Presidente del C. A. del ferrocarril } \\
\text { Orleáns-Burdeos } \\
\text { Administrador del ferrocarril Or- } \\
\text { leáns-Burdeos y del Tours-Nantes }\end{array}$ & \multirow[t]{7}{*}{$\begin{array}{l}\text { Presidente del } \\
\text { Comité de París }\end{array}$} \\
\hline ` Barón Juan Augusto Sarget & Burdeos & $\begin{array}{l}\text { Regente del Banco de Burdeos, } \\
\text { Caballero de la Legión de Honor y } \\
\text { administrador del ferrocarril Or- } \\
\text { leáns-Burdeos y del Tours-Nantes }\end{array}$ & \\
\hline $\begin{array}{l}\text { * Pablo Desbassayns, barón } \\
\text { de Richemont }\end{array}$ & París & $\begin{array}{l}\text { Administrador del ferrocarril Or- } \\
\text { leáns-Burdeos }\end{array}$ & \\
\hline * José Javier de Uribarren & París & Banquero & \\
\hline * Francisco Javier de Ezpeleta & Burdeos & $\begin{array}{l}\text { Director del ferrocarril Burdeos- } \\
\text { Cette y banquero }\end{array}$ & \\
\hline * Salustiano de Olózaga & París & Ex diputado a Cortes y propietario & \\
\hline * Juan Augusto Sarget (hijo) & Burdeos & Capitalista y propietario & \\
\hline \multicolumn{4}{|l|}{ GRAN BRETAÑA } \\
\hline * John Easthope & Londres & Baronet y miembro del Parlamento & \multirow[t]{5}{*}{$\begin{array}{l}\text { Presidente del } \\
\text { Comité de Lon- } \\
\text { dres }\end{array}$} \\
\hline * Guillermo Mackenzie & Liverpool & $\begin{array}{l}\text { Ingeniero, empresario de caminos } \\
\text { y director de varios ferrocarriles }\end{array}$ & \\
\hline * A. Lewis Gower & Londres & Director del Banco de Inglaterra & \\
\hline${ }^{*}$ Pedro Juan de Zulueta & Londres & $\begin{array}{l}\text { Gran Cruz de Isabel la Católica y } \\
\text { banquero }\end{array}$ & \\
\hline * Cristóbal de Murrieta & Londres & Banquero & \\
\hline
\end{tabular}

FUENTE: Empresa del camino de fierro de Madrid á Irun por Bilbao, Imprenta y litografía de Delmas e Hijo, Bilbao, $1846^{27}$.

27 Según el Título V, art. $27 .^{\circ}$ de los Estatutos de la empresa, formarian parte del consejo de administración las siguientes personas: Mazarredo, Arguinzóniz, Calderón, Ceriola, Uribarren, Murrieta, Victoria de Lecea, Manuel M. a Uhagón, Arrieta Mascárua, Pedro Pascual Uhagón, Orbegozo, Guillermo Uhagón, Epalza, Mackenzie, Barry, el barón Sarget, el duque de Mouchy y el barón de Richemont. Ahora bien, "el nombramiento de las personas que forman el complemento de los miembros del consejo de administración tendrá lugar de comun acuerdo entre los Señores Barry y Mackenzie y los Señores Victoria 
No se trata de hacer un estudio prosopográfico de los componentes de este consejo de administración, pero sí resulta interesante hacer un pequeño análisis del mismo ${ }^{28}$. Empezando por los domiciliados en España, observamos que mayoritariamente eran miembros de la burguesia bilbaina, que, como ya se ha dicho, fue la gran impulsora de este proyecto. Es más, incluso el presidente de la empresa, Manuel Mazarredo, era de Bilbao, a pesar de estar domiciliado en Madrid por sus elevados cargos. Hombre de prestigio, que había sido ministro de la Guerra (512-1843 a 3-5-1844), desde su cargo en la presidencia podria jugar un importante papel para allegar capitales de la nobleza y burguesía madrileñas. Por lo demás, los otros tres miembros domiciliados en la capital del reino eran banqueros, razón por la cual también podrían tratar de atraer inversores a la empresa. Otro tanto se podría decir incluso de algunos de los miembros domiciliados en Bilbao, como era el caso de Tomás José de Epalza y Pedro Pascual Uhagón. Ahora bien, aqui habría que señalar, además, que ambos eran destacados comerciantes de la villa. En concreto, Epalza había conseguido hacer una considerable fortuna durante su permanencia en La Habana, animado por Antonio López López, promotor de importantes transacciones mercantiles y de negocios entre España y sus colonias. Además, fue socio fundador de la importante empresa siderúrgica Santa Ana de Bolueta, desempeñando en 1841 el cargo de secretario y tesorero, siendo miembro de su consejo de administración tres años después ${ }^{29}$. Por lo demás, Pedro Pascual Uhagón, como ya se ha dicho, había estado implicado en este proyecto ferroviario desde el primer momento, al formar parte junto con Gabriel M. ${ }^{\text {a }}$ de Ybarra de la comisión formada por la Junta de Comercio de Bilbao a finales de 1844.

Entre los domiciliados en Bilbao sobresalen igualmente algunos grandes propietarios de la villa, como era el caso de Federico Victoria de Lecea, quien asumió la vicepresidencia de la empresa. Como se sabe, tanto él como Manuel M. ${ }^{a}$ Uhagón fueron designados por el Ayuntamiento de la capital vizcaína el 30 de diciembre de 1844 para constituir la comisión municipal que se encargara de este asunto. Lo mismo podríamos decir de Arguinzóniz y Arrieta Mascárua respecto de la mencionada comisión de la Diputación designada el 25 de enero de 1845. En estos dos últimos casos, ambos tenían el prurito de haber sido diputado general de Vizcaya y diputado a Cortes, respectivamente, con lo que es posible suponer que sus redes de influencia fueran notables. En definitiva, vemos cómo todas aquellas personas que habían formado parte de las tres comisiones mencionadas y que, por tanto, se habian implicado directamente en el proyecto desde sus inicios, pasaron

de Lecea y Uhagón". Estas fueron las personas que completan la tabla adjunta. Estos Estatutos están recogidos en Empresa del camino de fierro de Madrid á Irun por Bilbao, Imprenta y litografía de Delmas e Hijo, Bilbao, 1846.

${ }^{28}$ En este sentido, para los domiciliados en Bilbao, pueden consultarse, principalmente, AGiraeazKUENAGA y otros (1993): voces Arguinzóniz, Arrieta Mascárua, Epalza, P. P. Uhagón y Victoria de Lecea; y Agirreazkuenaga (dir.) (1995): voz G. Uhagón. Sobre Victoria de Lecea, véase también ARBAIzA Y MARTINEZ RUEDA (1989), pp. 99-107. Sobre los inversores bilbainos de estos años, véase además GaLARZA (1996).

${ }^{29}$ AgirREAZKuENAGa y otros (1993), p. 358. Sobre esta empresa, véase también Alonso, Erro y Arana (1998). 
a formar parte de este primer consejo de administración, con la sonada excepción de Gabriel M. ${ }^{\text {a }}$ de Ybarra, quien ya no figuraba en la comisión creada poco después de la concesión del camino de hierro de Madrid a Irún por Bilbao a Victoria de Lecea y Arrieta Mascárua mediante la Real Orden de 16 de agosto de $1845^{30}$.

Decimos sonada porque tenemos constancia de que la sociedad Ybarra, Mier y cía llegó a estar interesada en la construcción de este ferrocarril. En efecto, a la altura de 1845 los Ybarra, tratantes de hierro en esos momentos, albergaban ciertas esperanzas de que esta vía férrea pudiera llevarse a cabo, de manera que en una carta dirigida al siderúrgico malagueño Manuel Agustín Heredia, uno de los empresarios más poderosos de su época, señalaban que la construcción del ferrocarril de Madrid a Bilbao dependía únicamente del informe favorable del ingeniero director del proyecto. Además, en esta misiva, fechada el 27 de mayo de 1845 , es decir, unos meses antes de la concesión de la línea, se afirmaba que «si esto tiene lugar el fierro ha de subir", por lo que se preparaban para "hacer trabajar un horno alto que tiene un amigo", refiriéndose a la fábrica siderúrgica de La Merced de Guriezo, en Cantabria ${ }^{31}$. En este sentido, no debemos olvidar que los Ybarra habían decidido invertir parte de su capital en esta fábrica, espoleados por la creación de la siderurgia de Santa Ana de Bolueta y animados por el posible papel que debian desempeñar en este sector en un futuro próximo ${ }^{32}$. Sin duda, la construcción de este ferrocarril aseguraría la colocación del hierro y habría de ser un claro aliciente para dedicarse plenamente a la producción de acabados.

Incluso, cabe mencionar la importante inversión que llevaron a cabo en el llamado Camino de las Encartaciones, es decir, aquél que unía Bilbao con el norte de Castilla. En este caso el objetivo primordial de los Ybarra era el de mejorar las comunicaciones de la zona minera y facilitar las expediciones de hierro hacia el resto de la península por Valmaseda ${ }^{33}$. Sin duda, los intereses económicos de los Ybarra en esta zona eran claros, especialmente en el coto minero de Somorrostro. Por todo ello resulta sumamente extraño que no llegaran a participar en este consejo de administración, más aún cuando dos buenos amigos de la familia, José Javier Uribarren y Cristóbal de Murrieta, titulares de grandes propiedades en Santurce y Baracaldo, respectivamente, formaban parte del mismo. Incluso los Ybarra los habian interesado en el Camino de las Encartaciones precisamente por la tenencia de estas posesiones ${ }^{34}$. También desconocemos si los Ybarra llegaron a comprar acciones de la empresa, pero los indicios parecen ser negativos, ya que en el balance de Ybarra, Mier y Compañía de 1849 figura una cantidad de 623.200 reales de vellón ( $8 \%$ del activo total) en carreteras de Vizcaya, correspondiendo la

${ }^{30}$ Dicha comisión estaba integrada por Arguinzóniz, Arrieta Mascárua, Victoria de Lecea, Manuel M. ${ }^{\mathrm{a}}$ Uhagón, Pedro Pascual Uhagón, Orbegozo, Guillermo Uhagón y Epalza (Empresa del camino de fierro de Madrid á Irun por Bilbao, Imprenta y litografía de Delmas e Hijo, Bilbao, 1846: Documentos anejos).

${ }^{31}$ Archivo Ybarra, legajo 280: carta de 27 de mayo de 1845 de Ybarra, Mier y Compañía a Manuel Agustín Heredia, citada por Díaz MORLÁN (2002), p. 73.

${ }^{32}$ DiAZ MORLAN (2002), p. 69.

${ }^{33}$ Idem, p. 65.

34 Ibidem. 
mayor parte de esta inversión al mencionado Camino de las Encartaciones y una porción menor al de Lequeitio a Muniqueta ${ }^{35}$.

Entre los miembros domiciliados en Francia sobresalen los españoles, el banquero José Javier Uribarren y el político Salustiano de Olózoga. Oriundo de Lequeitio, José Javier Uribarren poseía en compañía de su hermano Fabián una casa de banca en París, habiéndose interesado desde 1844 por la fábrica de Santa Ana de Bolueta, pretendiendo incrementar asi sus intereses siderúrgicos. De hecho, es probable que vieran ciertas posibilidades de negocio en una construcción del ferrocarril que, sin duda, debería demandar productos siderúrgicos. Por su parte, Olózaga, abogado de profesión y líder destacado del Partido Progresista, llegó a presidir años más tarde, en 1850, la comisión elegida por el Congreso para dictaminar el proyecto de ley general de ferrocarriles presentado por Manuel Seijas Lozano, ministro de Comercio, Instrucción y Obras Públicas del gabinete presidido por Narváez ${ }^{36}$.

Por lo demás, hay que señalar la presencia de miembros franceses con importantes puestos de responsabilidad en compañías ferroviarias, sobre todo en la de Orleáns a Burdeos. Esto no es extraño si tenemos en cuenta que la línea se planteaba entre Madrid e Irún, es decir, como un enlace de la capital de España con la frontera francesa. Al llegar el tendido hasta Irún aumentaban las posibilidades de que el trazado continuara hasta París por Burdeos. De ahí que los directivos de esa compañía pudieran interesarse por el proyecto. Es lógico, pues, que el propio duque de Mouchy, presidente del consejo de administración del ferrocarril Orleáns-Burdeos, no sólo figurase como miembro del consejo de administración del camino de hierro de Madrid a Irún por Bilbao, sino que, además, fuera nombrado presidente del comité de esta línea en París. Algo parecido se podría decir del propio barón Sarget, personaje de especial relevancia en los negocios de la capital bordelesa.

En cuanto a los domiciliados en Gran Bretaña, destaca también la presencia de dos banqueros de origen vasco. Por un lado, Cristóbal Murrieta, originario de Santurce y miembro de la casa de banca londinense Aguirre-Solarte y Murrieta, la cual desde finales de la década de 1830 formaba parte de un circuito financiero que sirvió de base para realizar trasvases de capital americano a Europa, participando, además, en el tráfico de coloniales y, sobre todo, en la concesión de préstamos $^{37}$. Por otro, Pedro Juan Zulueta, nacido en Cádiz e instalado en Londres, quien se convirtió junto con otros miembros de esa misma familia en uno de los más importantes comerciantes de Cuba ${ }^{38}$. Junto a éstos, sobresale la presencia de sir John Easthope como presidente del comité de Londres y que, debido a su per-

35 Idem, pp. 64 (nota 10) y 335-336 (Balance de 1849).

36 Mateo del Peral (1978), pp. 49 y ss.

${ }^{37}$ GÁRATE (2000).

38 Bahamonde Y CAYUela (1992), cap. 7. Sobre los intereses económicos españoles en Cuba, véanse, fundamentalmente, este trabajo y el de MOREno Fraginals (1995 y 2002). 
tenencia a la aristocracia y al Parlamento británico, posiblemente pudiera contar con una buena red de relaciones con vistas a favorecer las inversiones en este proyecto. Lo mismo cabría pensar de Lewis Gower, director del Banco de Inglaterra. Finalmente, la presencia de Mackenzie era obligada, por sus elevados conocimientos en materia ferroviaria y por haber llevado buena parte del peso de las conversaciones con Federico Victoria de Lecea y Pedro Pascual Uhagón en París.

Dicho esto, debemos comentar también que el domicilio de la sociedad se estableció en Bilbao, pudiendo el consejo de administración delegar en una comisión de dirección, compuesta por al menos tres miembros y sita en esta misma ciudad, todos o parte de sus poderes. Aunque, como ya se ha señalado, se establecieron igualmente dos comisiones ejecutivas en París y Londres, respectivamente, debido a ese carácter internacional que presentaba la compañia (art. 35). En verdad, su domicilio social no duraría mucho en la capital vizcaína, siendo trasladada a Madrid. Además, se fijó un capital de seiscientos millones de reales, dividido en 300.000 acciones de cien pesos fuertes cada una, siendo preciso desembolsar una décima parte de su valor en el momento de la suscripción (art. 9). Hasta la puesta en explotación de la primera sección del camino de hierro se pagaría anualmente a los accionistas un $4 \%$ de interés sobre las cantidades que hubieran desembolsado. Interés que se incrementaría al $5 \%$ anual una vez puesta en explotación una sección de dicho ferrocarril (art. 23). Es más, todos los vocales del consejo de administración deberían poseer cien acciones (art. 28). Por último, como ingenieros directores de la compañía figuraban Alexander Ross y Calixto Santa Cruz.

\section{EXPECTATIVAS ECONÓMICAS Y LA CRISIS DE LA DÉCADA DE 1840}

Ya se ha mencionado más arriba las posibilidades económicas que el traslado de aduanas decretado por Espartero en 1841 trajo consigo para los productores y comerciantes vascos. Este hecho no vino sino a sumarse a las propias medidas dictadas por los liberales en el poder para alterar el marco institucional y favorecer así el desarrollo económico del país. De hecho, coincidiendo con la propia Real Orden de 31 de diciembre de 1844 se detectaba un cierto progreso económico en regiones tales como Cataluña, País Vasco, Valencia o la misma Madrid. Asi, algunas de las propuestas ferroviarias realizadas durante estos años insistieron precisamente en esta nueva realidad económica. Fue el caso, por ejemplo, de la Memoria escrita por Federico Victoria de Lecea y José Miguel Arrieta Mascárua el 16 de enero de 1846 respecto del camino de hierro entre Madrid e Irún pasando por Bilbao $^{39}$. En un momento en que las series estadísticas en España eran muy deficientes, los autores recurrieron a distintas fuentes, tanto públicas como privadas, para llegar a la estimación de unos posibles ingresos de 103.500 .000 reales de ve-

39 AFV: Administrativo, Obras, transportes y comunicaciones: Ferrocarril Madrid-Irún, Registro 1, legajo 1.: Memoria de F. Victoria de Lecea y J. M. Arrieta Mascárua, recogida también en Empresa del camino de fierro de Madrid á Irun por Bilbao, Imprenta y litografía de Delmas e Hijo, Bilbao, 1846. 
Ilón anuales en caso de que se construyera el mencionado ferrocarril. El cual, según se deduce de la Memoria, habria de contribuir a vertebrar el territorio por el que discurriese, siviendo así para unificar el mercado del norte de España, terminar con el aislamiento de determinadas zonas y con los mercados meramente locales, reactivar la economía de las provincias afectadas y de las limítrofes, canalizar los excedentes de producción hacia el comercio exterior y favorecer el traslado de pasajeros.

Estimación de ingresos brutos anuales del ferrocarril Madrid-Irún por Bilbao

\begin{tabular}{c|rr} 
Concepto & \multicolumn{2}{|c}{ Reales de vellon \% } \\
Cereales & 30.000 .000 & 28,98 \\
Vino & 4.500 .000 & 4,34 \\
Hierros & 3.000 .000 & 2,89 \\
Carbón de piedra y minerales & 5.500 .000 & 5,31 \\
Viajeros & 34.480 .000 & 33,31 \\
Pescado fresco & 6.000 .000 & 5,79 \\
Efectos de comercio de importación & 13.500 .000 & 13,04 \\
Efectos de comercio de exportación & 1.500 .000 & 1,44 \\
Artículos varios & 2.000 .000 & 1,93 \\
Correos, conducción de tropas, convoyes especiales, etc. & 3.020 .000 & 2,91 \\
\hline TOTAL & 103.500 .000 & 100,00 \\
\hline
\end{tabular}

FUENTE; Memoria de F. Victoria de Lecea y J. M. Arrieta Mascárua, publicada en Empresa del camino de fierro de Madrid á Irun por Bilbao, Imprenta y litografia de Delmas e Hijo, Bilbao, 1846.

De las partidas contempladas, sólo tres abarcarian las tres cuartas partes de los ingresos brutos de la compañía, siendo la más importante de ellas la referida al tráfico de viajeros. Basándose en los datos que había sobre el movimiento de personas en los medios de transporte existentes en la época, calcularon que aquél, con la puesta en marcha del ferrocarril, se multiplicaría por tres. En cuanto a los cereales, creían en la importancia que este comercio podía adquirir con la modificación de las leyes inglesas sobre esta materia y el descenso en el precio de transporte de los trigos castellanos gracias a la puesta en marcha de este camino de hierro. De esta forma, si en 1842 la mayor parte de los 15 millones de fanegas de trigo que habia importado Inglaterra provenía del Báltico, de Italia y del mar Negro, se confiaba en que buena parte de estas expediciones se pudieran hacer desde el puerto de Bilbao con cereales castellanos. Por último, por lo que se refiere a los efectos del comercio de importación, géneros coloniales y extranjeros destinados al consumo interior, se afirmaba que en 1844 la importación de estos productos por las aduanas de Irún, San Sebastián, Bilbao y Santander habia sido de más de seis millones de arrobas, señalándose que una modificación de las tarifas, una mayor 
facilidad en los cambios y un aumento de la propia industria nacional podrian aumentar este tráfico en una vez y media.

A estos beneficios brutos habría que restar los gastos de explotación, estipulados en 46.575 .000 reales de vellón, lo que reducía el ingreso neto a 56.925.000 reales. Se trataba, evidentemente, de unos cálculos optimistas, aunque en algunas de las partidas hablaran incluso de la modestia de los incrementos. En efecto, podía resultar factible pensar que el ferrocarril podría estimular el desarrollo económico de las provincias por las que pasara, pero en algunos casos no bastaba únicamente con la puesta en marcha de este nuevo medio de transporte, sino que se abogaba por algunos cambios en la propia política comercial, lo cual no era tan fácil de asegurar.

Al final, estas previsiones chocarían con la tozuda realidad, ya que las fluctuaciones interanuales de los rendimientos y de las cosechas en el campo español siguieron siendo muy amplias entre 1830 y 1880 , superando con frecuencia el $40 \%$ respecto de la producción media del periodo y, en ocasiones, el $60 \%$. De esta forma, España sufrió recurrentes crisis de subsistencias en 1847, 1856-1857, 1868 y 1882 , con graves repercusiones en la mortalidad. De hecho, las alzas del precio del trigo fueron intensas en 1835, 1847, 1857, 1868 y aún en 1882. En tales circunstancias se autorizó la importación de cereales, con el fin de paliar los efectos de estas crisis. Por consiguiente, esa idea de que España podría convertirse en exportador privilegiado de trigos y harinas a la Europa del norte parecía desvanecerse ante semejantes crisis. Si entre 1850 y 1879 las exportaciones de trigo y harina alcanzaron 2,4 millones toneladas, las importaciones sumaron 3 millones, de suerte que lo que hubo fue un déficit neto ${ }^{40}$.

En verdad, se podría decir que la constitución de la Compañia del camino de fierro de Irun á Madrid por Bilbao tuvo lugar en un mal momento, ya que a mediados de los años cuarenta se produjo en Europa y América una fuerte crisis financiera, que, como ya se ha señalado, se dejó sentir en algunas bolsas europeas a finales de 1845. Una crisis que no sólo fue financiera, sino también agrícola en un buen número de países europeos, lo que generó una importante depresión económica en esos años. Depresión que estuvo acompañada, además, en muchos casos por una ola revolucionaria de carácter democrático en 1848. Como es lógico, España no fue ajena a esta crisis económica. En efecto, tal como recordara Gabriel Tortella, una vez concluida la Primera Guerra Carlista se vivió un ambiente de euforia en el mundo de los negocios, de forma que se produjo una clara recuperación de las inversiones industriales en Cataluña, se puso en marcha el proceso de industrialización en el País Vasco y aumentó notablemente la actividad en la Bolsa de Madrid y en los círculos mercantiles de Barcelona ${ }^{41}$. Sin duda, uno de los factores que aumentaron el optimismo de esta época fue una mejora en la situación de la deuda pública, gracias a la reforma Mon-Santillán de 1845. Semejante am-

40 Pascual y SudRIÀ (2002), pp. 207-214.

41 Tortella $\left(1982,2 .^{a}\right.$ ed.), p. 42. 
biente, pues, afectó igualmente a los ferrocarriles, como ya se ha dicho, si bien sólo tres compañías llegaron a emprender el tendido de sus líneas en 1846-1847: la de Barcelona-Mataró, la de Madrid-Aranjuez y la de Langreo-Gijón.

Estos proyectos, no obstante, se vieron interrumpidos por la primera clara crisis capitalista española, la de 1847-1848, que supuso que muchas sociedades anónimas suspendieran pagos, algunos ferrocarriles aplazaran sus obras (excepto el de Barcelona-Mataró, que se inauguró en 1848) y muchos industriales textiles despidieran a sus obreros. A este sombrío panorama se sumó igualmente una importante crisis agrícola que dio lugar a la mencionada crisis de subsistencias de 1847. La consecuencia financiera de esto fue la ley de sociedades de 1848 , sumamente restrictiva, y la ley bancaria de 1849 , la cual prohibió la fundación de nuevos bancos de emisión. Sólo la nueva ley bancaria de 1851 levantó esta prohibición, aunque estableció un tope a la circulación fiduciaria igual al capital desembolsado ${ }^{42}$. Es más, desde el punto de vista ferroviario, ni siquiera la ley de 20 de febrero de 1850, que permitía que se concediera un interés de hasta un $6 \%$ a los capitales invertidos en caminos de hierro, sivió inicialmente para avivar el negocio ${ }^{43}$. Por consiguiente, en esta situación de crisis, tanto nacional como internacional, no resulta extraño que el proyecto de ferrocarril entre Madrid e Irún por Bilbao también se viera seriamente afectado. De hecho, en una reunión mantenida el 6 de noviembre de 1846 en Madrid se decidió no emitir acciones en esta capital debido a la escasez de metálico existente por las extracciones hechas hacia las provincias y el extranjero y por numerosas empresas que se habian creado últimamente ${ }^{44}$.

\section{UN NUEVO EMPUJE PARA LA LÍNEA MADRID-IRÚN POR BILBAO}

La crisis económica que vivió el país durante estos años no fue realmente un obstáculo para que la empresa del camino de hierro entre Madrid e Irún continuara con sus propósitos, sobre todo, por lo que se refiere a sus miembros vizcaínos, quienes más esfuerzos realizaron para seguir adelante con el cometido que se habían propuesto. Así, los planos de la sección que más les interesaba, la comprendida entre Bilbao y Burgos fueron realizados por Santa Cruz y remitidos al Ministerio de Obras Públicas, siendo aprobados por Real Orden de 10 de noviembre de 1848. La crisis, en verdad, fue un contratiempo, que no hizo sino retrasar sus planes, nunca frustrarlos, puesto que en 1851 nos encontramos con renovadas energías para proseguir con el proyecto. En opinión de los miembros del consejo de administración de la compañía, las circunstancias empezaban a ser "bonancibles» y

42 TORTElLa (1982, 2.a ed.), p. 43. Sobre esta crisis, véanse también Bernal Llorens (2000) y LópezMORELL (2002), pp. 24-29.

${ }^{43}$ El Orden, 23-7-1851: "Dictamen de la comision sobre la prolongacion del ferro-carril de Aranjuez á Almansa, y construccion de los de Madrid á Irun y de Alar á Santander».

${ }^{44}$ ACCB: Fondo Victoria de Lecea, legajo 8A, doc. n. ${ }^{\circ} 34$ : Acta del Comité Ejecutivo en Madrid (6 de noviembre de 1846). 
los capitales no escaseaban, por lo que era necesario ganar el tiempo perdido, toda vez que podían apreciarse importantes cambios de signo en la economía española del momento, la cual parecía comenzar a recuperarse ${ }^{45}$. Cambios a los que se uniría también una nueva actitud hacia los ferrocarriles por parte del gobierno de Narváez, consciente de que la Real Orden de 31 de diciembre de 1845 era insuficiente y no había dado los resultados esperados, ya que únicamente estaban abiertos al público los casi treinta kilómetros que había entre Barcelona y Mataró y se hallaban en construcción medio centenar en las proximidades de Madrid y en la zona minera de Asturias, cuando las concesiones otorgadas alcanzaban los 7.653 kilómetros ${ }^{46}$.

Cada vez se veía como más apremiante la elaboración de una ley general de ferrocarriles, labor a la que dedicó sus esfuerzos el ya mencionado ministro Seijas Lozano, cuya propuesta fue analizada en enero de 1850 por una comisión parlamentaria presidida por Olózaga. Esta comisión continuó con sus trabajos durante varios meses, llegando a señalar entre las líneas más importantes a realizar aquélla que uniría Madrid con Irún, tocando en alguno de los puertos del mar Cantábrico. Lo que viene a significar que el proyecto ya no era sólo relevante para sus impulsores, la burguesía vizcaína, sino también para los propios intereses nacionales. Aunque al cesar en su gestión el 29 de noviembre de 1850 Seijas Lozano, que pasó a ocupar la cartera de Hacienda, la idea de una ley general de ferrocarriles perdió apoyo oficial, siendo reavivada por la oposición.

Ahora bien, el Gobierno de Narváez cayó el 14 de enero de 1851, siendo sustituido por otro presidido por Bravo Murillo. Atento a la nueva situación, el consejo de administración del Madrid-Irún por Bilbao se dirigió a la Diputación de Vizcaya para que su diputado general, Rafael Guardamino, los representantes vascongados y, sobre todo, Pedro de Egaña utilizaran todos los medios a su alcance para conseguir que su propuesta saliera adelante, debido a los pasos dados por algunos diputados y senadores con vistas a la discusión en el Congreso del dictamen elaborado por la mencionada comisión parlamentaria de ferrocarriles. Existía el temor a "la parcialidad y la injusticia á que pudieran dar lugar ciertas influencias de localidad" frente a lo que se consideraba el interés general ${ }^{47}$. Efectivamente, no andaban descaminados los miembros del consejo, ya que unos meses más tarde, el 28 de junio, el Gobierno presentó en el Congreso un proyecto de ley para la construcción de un ferrocarril entre Aranjuez y Almansa por cuenta del Estado. Detrás de la propuesta debía estar Salamanca, provocando aquélla una viva polémi-

${ }^{45}$ AFV: Administrativo, Obras, transportes y comunicaciones: Ferrocarril Madrid-Irún, Registro 1, legajo 1: carta del 6 de marzo de 1851 del consejo de administración de la Compañia del camino de fierro de Madrid á Irun por Bibao a la Diputación Generał de Vizcaya.

46 Mateo del Peral (1978), p. 51.

47 AFV: Administrativo, Obras, transportes y comunicaciones: Ferrocarril Madrid-Irún, Registro 1, legajo 1: carta del 6 de marzo de 1851 del consejo de administración de la Compañía del camino de fierro de Madrid á Irun por Bilbao a la Diputación General de Vizcaya. 
ca en las Cortes, ya que vulneraba la ley provisional de 20 de febrero de 1850, en la que no se preveía financiación directa por la administración de ninguna obra ferroviaria $^{48}$.

Justo la víspera de que se presentara el proyecto de ley, el 27 de junio de 1851, la Diputación de Vizcaya se dirigía a Rafael Guardamino, entonces diputado a Cortes por el distrito de Bilbao, para que solicitara del Gobierno una prórroga del término de la concesión del ferrocarril Madrid-Irún por Bilbao, a punto de caducar, a la vez que se le instaba a que estuviera muy atento a los "conatos de postergarlo" y a las preferencias surgidas en torno a la línea de Alicante ${ }^{49}$. A partir de ese momento, pues, se podría decir que los intereses de ambos caminos de hierro empezaron a confluir, en la medida en que las gestiones de los vizcaínos se dirigieron hacia la consecución de los mismos beneficios que la línea auspiciada por Salamanca. A favor de la propuesta del Madrid-Irún por Bilbao se posicionó Salustiano de Olózaga, pero el peso de las negociaciones recayó en Guardamino, Victoria de Lecea y Pedro Pascual Uhagón, quienes el 17 de julio de 1851 se entrevistaron con Bravo Murillo para hablar de la propuesta. El presidente del consejo de ministros la acogió favorablemente y, de hecho, aquélla llegó a figurar en el proyecto de ley de 21 de julio formulado por la comisión nombrada en el Congreso para el estudio del ferrocarril de Almansa. Para ello, según manifestaban los vizcaínos, fue necesario hacer «algunas concesiones particulares", entre las que destacaban "la union y amalgama del camino de Madrid á Aranjuez con el nuestro" y el enlace ferroviario de la ciudad de Vitoria, bien directamente, bien mediante un ramal ${ }^{50}$. De esta forma, la línea del norte conseguia las mismas ventajas y medios de ejecución que la de Aranjuez a Almansa ${ }^{51}$.

Sin pérdida de tiempo, el Ayuntamiento y la Real Junta de Comercio de Bilbao nombraron dos comisionados, Pablo Ramón Aurrecoechea y Gabriel M. ${ }^{a}$ Orbegozo, para que mantuvieran sendas entrevistas con los representantes legítimos de las provincias de Álava, Logroño, Burgos, Valladolid y Palencia con el fin de recabar los apoyos necesarios para la construcción de la línea Madrid-Irún. Así, el objetivo de estos representantes era el asegurarse que las provincias se responsabilizaran del pago de un $3 \%$ de interés a los capitales invertidos en las secciones 2. ${ }^{a}$ y $3 .^{a}$ de la línea, es decir, entre Bilbao, Burgos y Valladolid, en caso de que el Gobierno no cumpliera sus compromisos (interés del $6 \%$ y del $1 \%$ de amortización para los capitales invertidos en la vía, tal como establecia la ley ferroviaria de 20 de febrero de 1850) o la explotación de la línea no produjera el $6 \%$ de interés prome-

48 Mateo del Peral (1978), p. 70. Sobre Salamanca y la construcción del ferrocarril de Aranjuez, véase el reciente trabajo LóPEZ-MORELL (2002).

49 AFV: Administrativo, Obras, transportes y comunicaciones: Ferrocarril Madrid-Irúr, Registro 1, legajo 1: carta del 27 de junio de 1851 de la Diputación de Vizcaya a Rafael Guardamino.

50 AFV: Administrativo, Obras, transportes y comunicaciones: Ferrocarril Madrid-Irún, Registro 1, legajo 1: carta del 18 de julio de 1851 de F. Victoria de Lecea, R. Guardamino y P. P. Uhagón a la Diputación de Vizcaya.

51. El dictamen del 21 de julio de la comisión puede leerse en El Orden, 23-7-1851. 
tido. Con semejante acuerdo de la provincias implicadas, tanto las dos instituciones mencionadas como la Diputación de Vizcaya consideraban que estas medidas serían suficientes para atraer los capitales necesarios para la construcción de las mencionadas secciones, aunque era preciso saber si el resto de las provincias interesadas estaban dispuestas a contribuir en la parte que a cada una le pudiera corresponder. $Y$ en esto consistió precisamente la misión de Aurrecoechea y Orbegozo, la cual tuvo lugar en el mes de septiembre, obteniendo, en general, una respuesta muy positiva. Aunque para que se implicaran las diputaciones de Alava y de La Rioja era preciso alterar el trazado, ya que exigieron que la línea pasara por Vitoria y Haro respectivamente ${ }^{52}$.

Paralela a la negociación llevada a cabo por estos dos comisionados, otro miembro de la empresa del camino de hierro Madrid-Irún, Pedro Pascual Uhagón, avanzaba en sus negociaciones con George Williams, representante de la casa londinense de William Jackson. El objetivo era allegar capitales extranjeros, fundamentalmente ingleses, para poder llevar a cabo la construcción del tramo comprendido entre la capital vizcaina y Valladolid. Las expectativas creadas por Uhagón en Williams fueron tales que el 8 de octubre de 1851 ambas partes llegaron a firmar en Madrid un contrato, en virtud del cual se crearía la sociedad Gran Ferrocarril del Norte de España con dirección central en Madrid. Uhagón, en nombre de los propietarios de la concesión, cedía a Williams y sus representados la mitad de las acciones que se emitieran para toda la línea, de manera que la empresa quedaba dividida en dos partes, una española y otra inglesa, distribuyéndose las cargas y beneficios en igual proporción. Por el momento, únicamente se abordarian las dos secciones intermedias mencionadas y el capital social quedaba fijado en 250 millones de reales, cantidad estipulada como necesaria para la construcción y para el material de explotación de esta parte de la vía férrea ${ }^{53}$.

Ahora bien, tanto la Diputación de Vizcaya como el consejo de administración de la empresa del camino de hierro consideraron este convenio demasiado prematuro, de suerte que no se ratificó de forma pública $y$, por consiguiente, quedó sin efecto. Era cierto que las negociaciones de Aurrecoechea y de Orbegozo habían discurrido por buen camino, pero era necesario llegar a acuerdos más sólidos con las provincias implicadas antes de iniciar las obras, puesto que eran éstas las que debian responsabilizarse del pago del $3 \%$ de interés a los capitales invertidos en el supuesto de que el Gobierno no efectuara sus compromisos o la explotación de la línea no produjera el $6 \%$ de interés prometido. Con tal objetivo, precisamente, se celebró en Burgos una importante reunión en diciembre de ese mismo año. En cambio, para Uhagón, la suspensión del contrato supuso una «mortal herida que

52 AFV: Administrativo, Obras, transportes y comunicaciones: Ferrocarril Madrid-Irún, Registro 1, legajo 1: informe del 9 de octubre de 1851 de P. R. Aurrecoechea y G. M. ${ }^{a}$ Orbegozo dirigido a la Diputación General de Vizcaya.

53 AFV: Administrativo, Obras, transportes y comunicaciones: Ferrocarril Madrid-Irún, Registro 1, legajo 1: copia del contrato en la carta del 11 de octubre de 1851 de P. P. Uhagón al consejo de administración de la empresa del camino de hierro de Madrid-Irún por Bilbao. 
recibe nuestra empresa, rechazando proposiciones que no volverán á repetirse, por mas que el consejo se figure lo contrario ${ }^{54}$.

Así, entre el 12 y el 16 de diciembre de 1851 se reunieron en Burgos los representantes de las provincias de Valladolid, Burgos, Logroño, Álava y Vizcaya, es decir, de aquéllas por donde habría de discurrir el tramo de vía férrea entre Bilbao y Valladolid, toda vez que los responsables de la empresa del camino de hierro de Madrid a Irún habian determinado que estas dos secciones eran las prioritarias. Por razones que ignoramos, la única provincia afectada que no envió representación a la capital burgalesa fue Palencia, a pesar de haber sido invitada. En el acta de la reunión se estimó que el coste de la vía férrea propuesta alcanzaria los 200 millones de reales, comprometiéndose las provincias afectadas a satisfacer la garantía mencionada del $3 \%$ a los capitales invertidos en ella. Además, se estableció que las contribuciones se harían en función del terreno que ocupase el ferrocarril en cada una de estas provincias, aunque con algunas correcciones ${ }^{55}$.

\section{JOSÉ DE SALAMANCA Y EL FIN DE UN PROYECTO}

Pocos días más tarde de la reunión de Burgos, el 19 de ese mismo mes, el Gobierno promulgaba un Real Decreto por el cual el Estado contrataba por su cuenta la construcción del ferrocarril de Aranjuez a Almansa con José de Salamanca y auxiliaba, tras confirmar la concesión, la obra de la línea férrea de Alar del Rey a Santander, a cuya promoción había contribuido el entonces ministro de Fomento Mariano Miguel de Reinoso, rico propietario de Valladolid y antiguo militar interesado en los negocios ferroviarios ${ }^{56}$. Precisamente, el comienzo de las obras de este camino de hierro suponía una amenaza directa para los comerciantes bilbaínos, ya que esta vía venía a poner en comunicación el puerto de la capital cántabra con Valladolid, mediante el Canal de Castilla, que empalmaba esta ciudad con Alar, donde comenzaba la línea. Más aún, el propio gobierno francés había decidido prolongar el tendido ferroviario desde Burdeos a Bayona, por lo que cabía pensar que pronto desearan alcanzar la frontera española, buscando la unión entre París y Madrid. Si ésta se realizaba por Valladolid, como cabía esperar, y no pasaba por Bilbao, las perspectivas económicas de su puerto habrían de resultar muy poco halagüeñas. De ahi la necesidad de la empresa del camino de hierro Madrid-Irún por Bilbao de actuar urgentemente y de conseguir los capitales necesarios para iniciar las obras.

54 AFV: Administrativo, Obras, transportes y comunicaciones: Ferrocarril Madrid-Irún, Registro 1, legajo 1: carta del 11 de octubre de 1851 de P. P. Uhagón al consejo de administración de la empresa del camino de hierro de Madrid-Irún por Bilbao.

55 AFV: Administrativo, Obras, transportes y comunicaciones: Ferrocarril Madrid-Irún, Registro 1, legajo 1: Acta de la reunión celebrada en Burgos por los comisionados de las provincias interesadas en el proyecto de ferro-carril (ejemplar impreso).

56 Mateo del Peral (1978), pp. 76-77. 
Cada vez se hacía más necesario contar con el apoyo de una persona bien relacionada tanto en el ámbito político como en el económico para sacar adelante el proyecto y evitar así la caducidad de la concesión. En este sentido, José de Salamanca podía resultar la figura idónea ${ }^{57}$. No sólo reunía ambas condiciones, sino que, además, hacía pocos meses se habían mantenido negociaciones con él, tal como se ha indicado. Sólo en este contexto, pues, podemos situar el convenio firmado en Vitoria el 4 de junio de 1852 entre el mencionado empresario y los representantes del consejo de administración del ferrocarril Madrid-Irún por Bilbao. En el acuerdo el consejo cedía a Salamanca el tramo del camino de hierro comprendido entre Madrid y Miranda o Haro, dejando la elección de una de las dos localidades para más adelante. Por su parte, Salamanca se obligaba a obtener del Gobierno el abono para cada legua comprendida entre Miranda o Haro y Bilbao e Irún de una mitad más del interés que consiguiera para cada legua de la sección entre Miranda o Haro y Madrid. También aquél se comprometía a hacer el depósito correspondiente a la sección de Bilbao a Burgos en el término de quince días para que la concesión no caducara, a comenzar las obras desde Miranda o Haro a esa ciudad castellana antes que por ninguna otra parte de la vía y a no iniciar la explotación de la sección entre Madrid y Valladolid antes que el tramo entre Miranda o Haro y Valladolid ${ }^{58}$.

Así, el Real Decreto de 4 de julio de 1852 otorgaba definitivamente la construcción del camino de hierro entre Madrid e Irún por Bilbao y consentía el convenio de cesión hecho entre la empresa concesionaria y José de Salamanca para el tramo comprendido entre la capital de España y el Ebro, reconociéndole los mismos derechos que a la empresa primitiva, a la que se le.concedía definitivamente la parte de la línea entre el Ebro e Irún. Además, el Estado pagaría a Salamanca 3.800.000 reales en obligaciones de ferrocarriles por cada legua del trazado Madrid-Burgos, sin incluir el coste de los túneles, y 4.500 .000 por cada legua del de esta ciudad a Miranda de Ebro. Para la distancia entre esta localidad e Irún por Bilbao, el Estado reconocía un valor de 5.500 .000 reales por legua para el efecto de la garantía del interés del $6 \%$ y $1 \%$ de amortización reconocido a la primitiva empresa concesionaria. El Estado adquiría la propiedad y explotación de este camino de hierro entre Madrid y el Ebro, conservando la empresa de Bilbao la propiedad y explotación del tramo entre el Ebro e Irún. Salamanca es reconocido como el constructor de la obra, fijándosele un plazo de tres años para la sección MadridEbro y cuatro hasta Irún, a contar desde la aprobación de los planos. La empresa debia depositar la cantidad de quince millones de reales para toda la línea, diez correspondientes a la primera sección y cinco a la segunda.

A partir de este momento los problemas de la línea fueron fundamentalmente dos, el de financiación y el legislativo propiamente dicho, ya que la ausencia de una

57 A este respecto, véase OtAZu (1987).

58 AFV: Administrativo, Obras, transportes y comunicaciones: Ferrocarril Madrid-Irún, Registro 1, legajo 1: copia del convenio en la carta del 5 de junio de 1852 de F. Victoria de Lecea y G. M.a Orbegozo a la Diputación General de Vizcaya. También aparece reproducido en El Heraldo (Madrid), 27-4-1853. 
ley general de ferrocarriles ocasionó importantes problemas tanto a Salamanca como a los primitivos concesionarios ${ }^{59}$. Fue entonces cuando se produjo el traspaso de la concesión de la compañía del ferrocarril Madrid-Irún por Bilbao al financiero malagueño, lo que, a la postre, venía a significar la liquidación de la misma, ya que José de Salamanca se comprometía, entre otras cosas, a transmitir la concesión a una nueva sociedad que se formaría al efecto y que sería la encargada de construir la línea, indicando, eso sí, que las obras habrían de comenzar por Bilbao ${ }^{60}$. A los pocos días, el 4 de marzo, aquél firmó una escritura de cesión de la mencionada concesión a favor de los capitalistas franceses e ingleses Ardoin, Ezpeleta, Grimaldi, Goldsmid, Rodhes y Wilkinson ${ }^{61}$, si bien la compañía prometida por Salamanca no se llegó a constituir, de forma que las obras no comenzaron y el proyecto terminó fracasando definitivamente, ya que el 13 de mayo de 1855 , en víspera de aprobarse la ley general de Ferrocarriles, la concesión caducó. Para Fernández Terreros, las dificultades planteadas por el paso del Guadarrama y las disputas entre Avila y Segovia para llevar la línea por sus respectivos territorios debieron influir también muy negativamente en la puesta en marcha del proyecto ${ }^{62}$. No obstante, más importancia debió tener el componente especulativo de la operación, al obtener los concesionarios un interés de un $6 \%$ anual por la cantidad depositada en el Tesoro Público español. Precisamente, los escándalos ferroviarios del momento hicieron que todos los expedientes de ferrocarriles fueran enviados al Consejo Real para su estudio ${ }^{63}$.

En este sentido, el propio informe de este Consejo de junio de 1853 fue también determinante, puesto que en él se disponía la suspensión de la subasta de la línea Madrid-Miranda hasta que se aprobara el trazado definitivo ${ }^{64}$. Esto no fue óbice para que Ezpeleta, Grimaldi y Ardoin, una vez que Goldsmid, Rodhes y Wilkinson hubieran cedido sus derechos al primero de ellos, llegaran a un acuerdo el 21 de septiembre de 1853 con Fernando Barrot, Eduardo Dolezac, Pedro Gil, Luis Lebeuf, Octavio Roger, el conde Simeón, Carlos Calderón, Gregorio López Mollinedo y Federico Victoria de Lecea para tratar de sacar adelante el proyecto mediante la creación de una sociedad anónima que, finalmente, tampoco llegó a constituirse ${ }^{65}$.

\footnotetext{
59 Sobre este aspecto, véase El Heraldo (Madrid), 27-4-1853.

60 ACCB: Fondo Victoria de Lecea, legajo 8A, doc. $n .^{\circ} 60$ : acta notarial de 20 de febrero de 1853 del traspaso de la concesión de 16 de agosto de 1845 a José de Salamanca.

61 El Heraldo (Madrid), 27-4-1853. El acuerdo original puede verse en Archivo Histórico de Protocolos de Madrid (AHPM): París (Consulado), 32.014, fols. 289-294.

62 Fernández Terreros (1974), p. 113.

63 Casañas (1979), p. 49.

64 García Venero (1948), p. 193. Precisamente, lo escándalos ferroviarios del momento hicieron que todos los expedientes de ferrocarriles fueran enviados al Consejo Real para su estudio (Casañas (1979), p. 49).

65 AHPM: París (Consulado), 32.014, fols. 432-435.
} 


\section{CONCLUSIONES}

A partir de la Real Orden de 1844 se abrió en España un período de numerosas solicitudes de concesiones ferroviarias en concordancia con las posibilidades que este nuevo medio de transporte ofrecia y con el despegue económico que vivió el país en esos años. Fue lo que sucedió con la "Concesión Vascongada" de 1845, cuando los vizcainos, deseosos de mejorar sus comunicaciones con el resto de la península, solicitaron que se les otorgara una línea que desde Madrid llegara hasta Irún y la frontera francesa, tocando el puerto de Bilbao. Lógicamente, se trataba de una línea de especial relevancia, ya que no servía únicamente a los intereses locales propiamente dichos, sino también a la unificación del mercado del norte y al empalme de España con Francia, con lo que la importancia de la misma era aún mayor. Sin embargo, en la España de esos años faltaban los tres factores básicos para el desarrollo de los ferrocarriles, a saber: capital, nivel técnico y empresarios capacitados para conjugar la técnica y el capital ${ }^{66}$. Posiblemente estas carencias se podían haber suplido con aportaciones externas y, de hecho, se intentó, pero quizás el mismo marco institucional no favoreció mucho la puesta en marcha de una vía férrea tan ambiciosa como la planteada por los vizcaínos. La falta de capitales ${ }^{67}$ y de una legislación adecuada debieron ser las principales causas de un fracaso que hicieron que aquellos, auténticos pioneros y promotores de la línea del Norte a mediados de los cuarenta, no sólo perdieran su concesión en 1855, sino que también quedaran marginados en el nuevo proyecto de ferrocarril del Norte impulsado por el grupo Péreire, el cual optó desde el primer momento por el camino más corto (Burgos, Vitoria, San Sebastián), quedando Bilbao fuera de este trazado. De esta manera, la ley general de Ferrocarriles de 1855 y las leyes de banca de 1856 no hicieron sino dar una nueva dimensión al negocio ferroviario español, hasta entonces muy parco en realizaciones, instaurando un nuevo marco institucional y favoreciendo la llegada de capitales foráneos.

\section{BIBLIOGRAFÍA}

AgiRREAZKuenaga, Joseba y otros (1993): Diccionario biográfico de los parlamentarios de Vasconia, 1808-1876, Parlamento Vasco, Vitoria; (dir.) (1995): Diccionario biográfico de los diputados generales, burócratas y patricios de Bizkaia (1800-1876), Juntas Generales de Bizkaia, Bilbao.

Alonso Olea, Eduardo J.; Erro, Carmen y AranA, Ignacio (1998): Santa Ana de Bolueta, 1841-1998, Santa Ana de Bolueta, Bilbao.

Arbaiza, Mercedes y Martínez Rueda, Fernando (1989): «La familia Victoria de Lecea en el siglo xIx: de rentistas a capitalistas (1798-1864)", Letras de Deusto, vol. $19, n .^{\circ} 43$.

66 Casares (1973), p. 48.

67 Para Garcia VenERo (1948, p. 187), «si el Estado hubiese satisfecho esa garantía (6\% de interés y $1 \%$ de amortización) en una sola vez y sobre los altos presupuestos que se calculaban para construir la linea, la Compañía franco-española hubiese ingresado una gran cantidad, que la habria permitido, acaso, un desahogo económico del que carecía. Pero D. Juan Subercase, que firmó la Real Orden accediendo a la petición, advertía que el interés y la amortización, se concederian sólo sobre un capital máximo de 600 millones de reales, y se iría librando a medida que fuese invertido en la línea". 
BaHAmonde, Ángel y Cayuela, José (1992): Hacer las Américas. Las elites coloniales españolas en el siglo XIX, Alianza, Madrid.

BERNAL LLORENS, Mercedes (2000): "The crisis of 1847-1848 and the regulation of company accounting in Spain", Accounting History, vol. 5, n. 2.

CAMERON, Rondo E. (1971): Francia y el desarrollo económico de Europa, 1800-1914, Tecnos, Madrid.

CASAÑas Magí (1977): “El ferrocarril en España, 1844-1868. Conclusiones en torno a una crisis", Investigaciones Económicas, $\mathrm{n} .{ }^{\circ} 4$

CASARES, Aníbal (1973): Estudio histórico-económico de las construcciones ferroviarias españolas en el siglo XIX, Instituto de Desarrollo Económico, Madrid.

DiAz MORLÁn, Pablo (2002): Los Ybarra. Una dinastía de empresarios (1801-2001), Marcial Pons, Madrid.

Fernández TerReros, Benedicta (1974): El proyecto de un ferrocarril Madrid-Irín pasando por Bilbao, $\mathrm{Me}$ moria de licenciatura inédita, Universidad de Deusto, Bilbao.

GALARZA, Arantzazu (1996): Los origenes del empresariado vasco. Creación de sociedades e inversión de capital, Bilbao (1850-1882), Beitia, Bilbao.

GÁRATE, Montserrat (2000): "Los Murrieta: comerciantes banqueros de Londres en el XIX", en MieZA, R. M. ${ }^{a}$ y Gracia, J. (eds.): Haciendo Historia. Homenaje a M. ${ }^{a}$ Angeles Larrea, Universidad del País Vasco, Bilbao.

GARCia Venero, Maximiano (1948): "Historia anecdótica del ferrocarril en España", en VVAA: Cien años de ferrocarril en España, t.1, Comisión Oficial para la conmemoración del primer centenario del ferrocarril en España, Madrid.

GonzÁlez PoRTILLA, Manuel y otros (1995): Ferrocarriles y Desarrollo. Red y mercados en el País Vasco, 1856-1914, Universidad del País Vasco, Bilbao.

LARRINAGA, Carlos (1999): Actividad económica y cambio estructural en San Sebastián durante la Restauración, 1875-1914, Instituto Dr. Camino de Historia donostiarra, San Sebastián.

LOPEZ-MorelL, Miguel A. (2002): "Salamanca y la construcción del ferrocarril de Aranjuez", en VVAA: Ferrocarril y Madrid. Historia de un progreso, Ministerio de Fomento y Fundación de los Ferrocarriles Españoles, Madrid.

MATEO del Peral, Diego (1978): "Los orígenes de la política ferroviaria en España (1844-1877)", en ARTOLA, M. (dir.): Los ferrocarriles en España. 1844-1943, t. I, Banco de España, Madrid.

Moreno Fraginals, Manuel (1995): Cuba/España. España/Cuba. Historia común, Crítica, Barcelona; (2002): El ingenio, Crítica, Barcelona.

OtazU, Alfonso de (1987): Los Rothschild y sus amigos en España (1820-1850), O.H.s, Madrid.

PASCUAL, Pere y SUdRIȦ, Carles (2002): «El difícil arranque de la industrialización (1840-1880)», en Comín, F.; Hernández, M. y Llopis, E. (eds.): Historia económica de España, siglos x-xx, Crítica, Barcelona.

SÁnCHEZ-Albornoz, Nicolás (1969): “El ferrocarril de Alar del Rey a Santander (1845-1874)», Moneda y Crédito, n. ${ }^{\circ} 108$

TORTELLA, Gabriel (1982, 2. a ed.): Los origenes del capitalismo en España, Tecnos, Madrid

Wals, Francisco (1987, 3. ${ }^{\mathrm{a}}$ ed.): Historia de los ferrocarriles españoles, Fundación de los Ferrocarniles Españoles, Madrid.

VVAA (1998): 150 Años de Historia de los Ferrocarriles Españoles, Anaya, Madrid. 